\title{
Simultaneous Determination of Linezolid and Levamisole Hydrochloride in a Fixed Dose Combination
}

\author{
Lalit Kumar, Yugvijay Singh Yadav, Mahalaxmi Rathnanand*
}

Department of Pharmaceutics, Manipal College of Pharmaceutical Sciences, Manipal University, Madhav Nagar 576 104, Manipal, Udupi, Karnataka, INDIA.

\begin{abstract}
Background: The combination of antibiotics with an immune-stimulant can be used for the prevention of antimicrobial resistance. Multilayer tablets of linezolid and levamisole hydrochloride can be a solution of this problem. Objective: Aim of the present study was to High Performance Liquid Chromatography method development and validation as per the International Council for Harmonisation guidelines for analysis of both the drugs simultaneously in a single unit dosage form. Methods: Ammonium acetate and acetonitrile in the ratio $65: 35(\% \mathrm{v} / \mathrm{v})$ was used as mobile phase. Ultra violet detection was carried out at $236 \mathrm{~nm}$ and flow rate was kept as $0.9 \mathrm{~mL} / \mathrm{min}$. Results: Linezolid and levamisole hydrochloride were found at $4.61 \mathrm{~min}$ and $6.45 \mathrm{~min}$ retention times, respectively. Conclusion: The study confirmed that the present method can be used for routine simultaneous analysis of linezolid and levamisole hydrochloride.

Key words: HPLC, Levamisole hydrochloride, Linezolid, Antibacterial resistance, Antimicrobial resistance.
\end{abstract}

\section{INTRODUCTION}

Antimicrobial resistance (AMR) has become a serious problem for a public health and it is a growing concern around the world. ${ }^{1}$ Progressively, governments around the world have started to pay attention to a serious problem that it threatens the successes of contemporary medicine. ${ }^{2}$ Antibacterial resistance (ABR) is an undisputable circumstance and will continue to grow in future. ABR is a main problem among various types of antimicrobial resistance. ${ }^{2}$ It causes economic and social implications which increases the cost of treatment, longer hospitalization and leads to high rate of hospitalization. ${ }^{1}$

Failure to tackle drug resistant infections will lead to at least 10 million extra deaths per year and cost the global economy up to $\$ 100$ tn $\left(£, 64\right.$ tn) by $2050 .^{3}$ As per Former Goldman Sachs chief economist Jim O’Neill, in a short term scenario AMR signifies a highly confident threatening in comparison of the climate change. ${ }^{3}$
Indian consumes the highest amount of antibiotics in the world, but Indians consume (at 10.7 units per candidate) less than half of the amount per candidate as in the US (at 22.0 units per candidate). China is the second-largest consumer of antibiotics (at 7.5 units per candidates). ${ }^{4}$ It has been reported that due to AMR the most populous counties such as India and China, may face 2 million and 1 million deaths a year, respectively by $2050 .{ }^{3}$ Past guidelines are partially effective for dealing with resistance issues. Therefore, novel approaches are required to solve the issues associated with antimicrobial resistance.

To avoid the antimicrobial resistance prescriber should have optimum knowledge of general medicines, genetic host factors, microbial virulence, immune-stimulants, physicochemical properties of drugs, etc. ${ }^{5}$ As the immune-boosting elements are used as alternatives to the antibiotics to reduce
Submission Date: 20-03-2017; Revision Date: 02-05-2017; Accepted Date: 13-07-2017.

DOI: $10.5530 / \mathrm{ijper} .51 .4 .91$ Correspondence: Dr. Mahalaxmi Rathnanand,

Department of Pharmaceutics Manipal College of Pharmaceutical Sciences Manipal University, Madhav Nagar 576 104, Manipal Udupi, Karnataka, INDIA. Mobile: +919743293826 E-mail: mahalaxmi.r@ manipal.edu

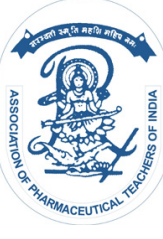

www.ijper.org 
the resistance, ${ }^{6}$ it is expected that the combination of antibiotics and immune-stimulant can overcome the problems of AMR. Hence in the present study we have formulated a fixed dose combination of an antibiotic (i.e., linezolid) and an immune-stimulant (i.e., levamisole hydrochloride) for the prevention of AMR.

Linezolid is an antibiotic and belongs to oxazolidinone class. The in vitro and in vivo spectrum of activity of linezolid is primarily against Gram-positive bacteria including methicillin-resistant Staphylococcus aureus (MRSA), streptococci, vancomycin-resistant enterococci (VRE), penicillin-resistant Staphylococcus pneumoniae (PRSP), etc. It is most commonly given in the skin/soft tissue infections and pneumonia. It may be used in a variety of other infections. ${ }^{7-14}$ But, the main problem associated with the drug is resistance.

Levamisole is one of the ideal candidates in this fixed dose combination, because of its immunomodulatory effect. ${ }^{15}$ It has been used as an immune-stimulator to stimulate the immune system either alone or in combination with other substances in the treatment of cancer, HIV, tuberculosis, etc. and to improve weight gain also. ${ }^{16,17}$ In the view of above facts, we have formulated multilayer tablets of linezolid and levamisole hydrochloride. But, no method has been reported till date for the estimation of linezolid and levamisole hydrochloride simultaneously in a same combination. Aim of present study was to develop and validate an HPLC method for the simultaneously estimation of both the drugs in multilayer tablets.

\section{MATERIALS AND METHODS}

\section{Reagents and Chemicals}

Linezolid was received as a gift sample from Glenmark Generics Ltd. (Mumbai, India) and levamisole hydrochloride was also obtained as a gift sample from Aurochem Pharmaceuticals Pvt. Ltd. (Mumbai, India). Avicel PH 101, sodium starch glycolate and glacial acetic acid were purchased from SD Fine Chem Ltd. (Mumbai, India). Acetonitrile (HPLC grade) was procured from Merck Specialities Pvt. Ltd. (Mumbai, India). HPMC E5 was procured from Lobachemie Pvt. Ltd. (Mumbai, India). Croscarmellose sodium was received as gift sample from Lupin Research Park (Pune, India). Aerosil was procured from Evonik Degussa India Pvt. Ltd. (Mumbai, India). Lactose was procured from Sisco Research Laboratories (Mumbai, India). Magnesium stearate was purchased from GS Chemical (New Delhi, India). Sodium lauryl sulphate was purchased from Nice Chemicals Pvt. Ltd. (Kerala, India). Ammonium acetate was purchased from Spectrochem Pvt. Ltd. (Mumbai,
India). Hydrochloric acid was procured from Suvidhinath Lab (Vadodara, India). Methanol was procured from Finar Ltd. (Ahmedabad, India). Milli Q (ultra-pure) water (more than $18.0 \mathrm{M} \Omega \mathrm{cm}$ resistivity) was produced in the Pharmaceutics department research laboratory.

\section{Instrumentation and Apparatus}

Analysis was performed using HPLC (LC-2010CHT, Shimadzu Corporation, Kyoto, Japan) connected with dual wavelength UV detector, quaternary low pressure gradient pumps, high-throughput auto-sampler and column oven was used for the present study. For data acquisition, monitoring and processing output chromatographs LC software solution 5.57 release was used. The mobile phase and stock solutions were prepared with Milli Q (ultra-pure) water, which was prepared in department research laboratory using Millipore water purification system (Direct-Q ${ }^{\circledR}$ 3, Millipore Corporation, Billerica, MA, USA). For weighing of the drug and standard chemicals sensitive analytical balance (Sartorius CPA 225D, Sartorius AG, Germany) was used. The prepared buffer was passed through $0.22 \mu$ membrane filter (Pall Pvt. Ltd., Bangalore, India) using a glass vacuum filtration assembly (Merck Millipore, Merck Life Science Pvt. Ltd., Mumbai, India) connected with rotary vacuum pump (Turbo Blower Manufacturer, Mumbai, India). The $\mathrm{pH}$ of buffer was measured with a $\mathrm{pH}$ meter (Eutech Instruments $\mathrm{pH}$ 510) using a glass electrode (Van London, Co., USA). Then the buffer was degassed using ultrasonic bath (Ultrasonic Cleaner15L, Equitron - Medica Instrument Mfg. Co., Mumbai, India) to reduce the noise in baseline.

\section{Preparation of Multilayer Tablets}

As shown in Table 1, the required quantity of linezolid blend was weighed and half of its amount was filled in die cavity and pressed slightly. Then weighed amount of levamisole hydrochloride blend was filled and above it remaining half amount of linezolid blend was filled and then it was punched using manually operated tablet punching machine. Multilayer tablet was prepared to prevent separation of layers.

\section{Preparation of Solutions \\ Preparation of Mobile Phase}

Mobile phase used for the present study was consist of ammonium acetate ( $\mathrm{pH} 4.0)$ and acetonitrile in the ratio $65: 35(\% \mathrm{v} / \mathrm{v})$. The $\mathrm{pH}$ of buffer was selected on the basis of high elution which was achieved after few trials. Ammonium acetate was used in a very low concentration $(20 \mathrm{mM})$ to prevent the precipitation and 
obstructions of HPLC system. The low concentration of buffer was chosen for column safety. ${ }^{18,19}$

\section{Preparation of Stock Solution of Linezolid}

Linezolid (10 mg) was weighed and dissolved in $1 \mathrm{~mL}$ of methanol and volume was made up to $10 \mathrm{~mL}$ with Milli Q water to obtain $1000 \mu \mathrm{g} / \mathrm{mL}$ of drug. The solution $(2.0 \mathrm{~mL})$ was taken and diluted with Milli Q water to get $80 \mu \mathrm{g} / \mathrm{mL}$ of drug.

\section{Preparation of Stock Solution of Levamisole Hydrochloride}

Levamisole hydrochloride $(11.78 \mathrm{mg}$, equivalent to $10 \mathrm{mg}$ of levamisole) was weighed and dissolved in few milli litre of Milli Q water. Then the volume was made up to $10 \mathrm{~mL}$ with Milli Q water to produce $1000 \mu \mathrm{g} / \mathrm{mL}$ of drug. The $250 \mu \mathrm{L}$ of solution was taken and diluted with Milli Q water to produce $10 \mu \mathrm{g} / \mathrm{mL}$ of drug.

\section{Preparation of Standard Solution}

The $1.5 \mathrm{~mL}$ solution of linezolid $(80 \mu \mathrm{g} / \mathrm{mL})$ was mixed with $1.2 \mathrm{~mL}$ solution of levamisole hydrochloride $(10 \mu \mathrm{g} / \mathrm{mL})$ and further diluted to $10 \mathrm{~mL}$ with mobile phase (buffer: acetonitrile 65:35\% v/v) to produce $12 \mu \mathrm{g} / \mathrm{mL}$ and $1.2 \mu \mathrm{g} / \mathrm{mL}$ for linezolid and levamisole, respectively. The mixture was injected $(20 \mu \mathrm{L})$ into HPLC system and peak area was calculated.

\section{Development of HPLC Method}

A simultaneous method for estimation of linezolid and levamisole hydrochloride in fixed dose combination by HPLC was developed adopting following conditions such as Genesis ${ }^{\circledR} \mathrm{C}_{18}$ column $(250 \mathrm{~mm} \times 4.6 \mathrm{~mm}$ id, $4 \mu \mathrm{m}, \mathrm{BDS} 120 \AA$ ) as a stationary phase, mobile phase as ammonium acetate $(\mathrm{pH} 4.0)$ and acetonitrile in the ratio 65:35 (\%v/v), flow rate $(0.8 \mathrm{~mL} / \mathrm{min})$, UV detector with wavelength (at isosbestic point) $236 \mathrm{~nm}$, column oven temperature at $25^{\circ} \mathrm{C}$, injection volume $20 \mu \mathrm{L}$ and run time $8 \mathrm{~min}$.

\section{Method Validation}

Method is validated as per the ICH Q2(R1) guidelines. ${ }^{19}$ The following typical parameters considered were considered for method validation. ${ }^{18,20-24}$

\section{Specificity}

Interference from placebo was determined at retention time of linezolid and levamisole hydrochloride using HPLC.

\section{Linearity}

The seven concentrations of each drug i.e. between 2 to $24 \mu \mathrm{g} / \mathrm{mL}$ for linezolid and between 0.2 to $2.4 \mu \mathrm{g} / \mathrm{mL}$ for levamisole were prepared. Each concentration was analysed thrice as independent samples by injecting 20 $\mu \mathrm{L}$ and the mean peak area for each concentration was calculated. Calibration curve was constructed by using observed peak area versus concentration of analyte. The coefficient of determinant $\left(\mathrm{r}^{2}\right)$ and linear regression were determined from the constructed calibration curve. ${ }^{18,24}$

\section{Precision}

Precision was performed as intraday and interday precision. ${ }^{18,24}$

\section{i. Intraday precision}

Peak area obtained from mixture of linezolid and levamisole standard solution was analysed two times in a day as six independent samples analysis at a time. Then the peak area and percent relative standard deviation (\% RSD) was calculated. ${ }^{18,24}$

\section{ii. Interday precision}

In this study, the mixture of linezolid and levamisole standard solution was analysed in two different days as six independent samples analysis at a time. Then the peak area and percent relative standard deviation (\%RSD) was calculated. ${ }^{18,24}$

\section{Robustness ${ }^{21,22}$}

\section{i. Effect of $p H$ of buffer}

The effect of $\mathrm{pH}$ of buffer was assessed with variations in $\mathrm{pH}$ by \pm 0.2 units. The standard mixture of both the drugs was analysed using the above developed HPLC method as three independent samples.

\section{ii. Effect of flow rate}

The effect of flow rate was determined with variations in flow rate by $\pm 0.1 \mathrm{~mL} / \mathrm{min}$. The standard mixture of both the drugs was analysed using the above developed HPLC method as three independent samples.

\section{iii. Effect of wavelength}

The effect of wavelength was assessed with variations in wavelength by $\pm 2.0 \mathrm{~nm}$. The standard mixture of both the drugs was analysed using the above developed HPLC method as three independent samples.

\section{Limit of detection and Limit of quantitation}

Limit of detection (LOD) and limit of quantitation (LOQ) were determined using the reported methods ${ }^{18,21-24}$ and formulae for determination of same are as given below: $:^{18,22,24}$

$$
\begin{aligned}
& \mathrm{LOD}=3.3 \times \frac{\mathrm{SD}}{\text { slope }} \\
& \mathrm{LOQ}=10 \times \frac{\mathrm{SD}}{\text { Slope }}
\end{aligned}
$$


Where, 'SD' is related to the least standard deviation value obtained in response and 'slope' is obtained from the linearity.

\section{Application of method in estimation of linezolid and levamisole hydrochloride in fixed dose combination}

Drug content in multilayer tablet was performed by the developed and validated HPLC method. Three tablets were crushed to powder and $230 \mathrm{mg}$ of powder was taken in $100 \mathrm{~mL}$ volumetric flask. Methanol-water (1:1) mixture was added in to the flask to dissolve the powder and was sonicated and the volume was made up to $100 \mathrm{~mL}$ with same solvent mixture. Solution was filtered using Whatmann filter paper (no 1). The $1.0 \mathrm{~mL}$ of filtrate was taken and further diluted with mobile phase to produce $10 \mathrm{~mL}$. The resultant solution was filtered through membrane filter with pore size $0.22 \mu$. This solution was injected $(20 \mu \mathrm{L})$ in HPLC system. Peak area was recorded for both the drugs and the drug content was calculated. The drug content was calculated using the below given formula:

$$
\text { Drug content }=100 \times \frac{\text { Obtained Concentration }}{\text { Theoretical Concentration }}
$$

\section{RESULTS AND DISCUSSION}

\section{Selection of Wavelength}

Wavelength of drugs was selected on the basis of isosbestic point of their wavelengths. At $236 \mathrm{~nm}$ both drugs showed the same absorbance (isosbestic point), hence $236 \mathrm{~nm}$ was selected as detection wavelength for HPLC.

\section{Method Validation}

\section{Specificity}

The developed method was used for estimation of linezolid and levamisole hydrochloride in fixed dose multilayer tablets. As shown in Figure 1, the retention times of linezolid and levamisole hydrochloride were found to be $4.61 \mathrm{~min}$ and $6.45 \mathrm{~min}$, respectively. It confirms the method is fast and also confirms the absence of interference of one drug on the estimation of another drug.

\section{Linearity}

The calibration curves were constructed for both the drugs by plotting the obtained HPLC peak area against concentration to get the coefficient values and linear regression equations. The correlation values obtained for linezolid and levamisole hydrochloride are 0.999 and 0.998 , respectively. The coefficient of determinant values are the evidence of strong relationship between

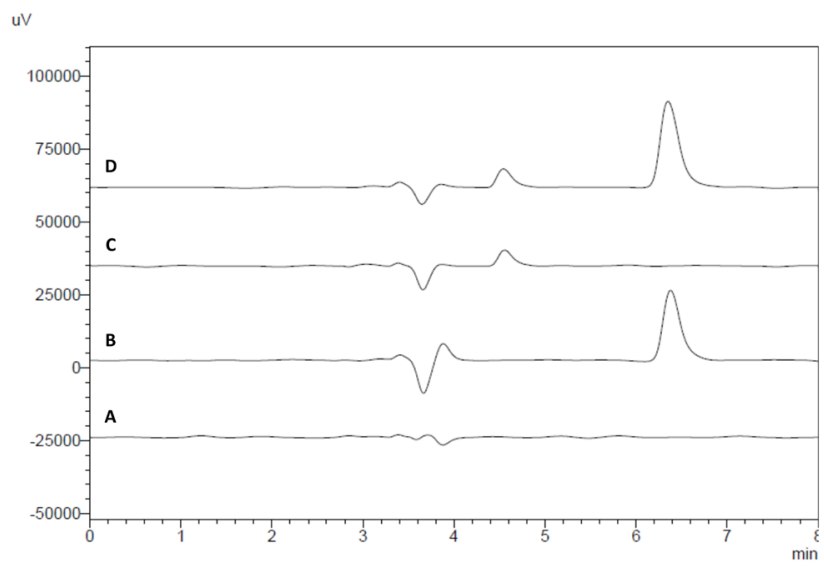

Figure 1: Chromatogram of placebo (A), levamisole hydrochloride (B), linezolid (C) and levamisole hydrochloride and linezolid in combination (D).

the peak area and concentrations. Similarly, the linear regression equations obtained for the linezolid and levamisole hydrochloride are 27149x +1028.5 and 43910x +6003.4 , respectively.

\section{Precision}

The percent relative standard deviation from intraday precision of linezolid and levamisole hydrochloride was found to be $0.91 \%$ and $0.94 \%$, respectively. Similarly, percent relative standard deviation from interday precision of linezolid and levamisole hydrochloride was found to be $1.14 \%$ and $1.85 \%$, respectively. The obtained relative standard deviation values are found to be within the range. Since as per the acceptance criteria of $\mathrm{ICH}$, the relative standard deviation values for intraday and interday precisions should be less than $1 \%$ and less than $2 \%$, respectively. The obtained results confirmed the method is precise.

\section{Robustness}

In all the deliberately altered chromatographic conditions ( $\mathrm{pH}$, wavelength and flow rate) the elution of drugs was remained same without any interference of impurities. The obtained percentage relative standard deviation (peak area) of both the drugs with the deliberately alterations in chromatographic conditions was found to be less than $2 \%$. The obtained results of the percent relative standard deviations of peak area are reported in Table 2.

\section{Limit of detection and Limit of quantitation}

LOD and LOQ were determined using reported methods on signal to noise ratio. ${ }^{18,21,22,24,25} \mathrm{LOD}$ values of linezolid and levamizole hydrochloride were found to be 0.635 $\mu \mathrm{g} / \mathrm{mL}$ and $0.051 \mu \mathrm{g} / \mathrm{mL}$, respectively. Similarly, LOQ 


\begin{tabular}{|c|c|c|}
\hline \multicolumn{2}{|c|}{ Table 1: Composition of multilayer tablet } \\
\hline Ingredients & $\begin{array}{c}\text { Linezolid layer } \\
\text { (mg/tablet) }\end{array}$ & $\begin{array}{c}\text { Levamisole hydrochloride layer } \\
\text { (mg/tablet) }\end{array}$ \\
\hline Linezolid & 600 & - \\
\hline Levamisole hydrochloride & - & 88 \\
\hline Avicel PH 101 & - & 10 \\
\hline HPMC E5 & - & 35 \\
\hline Lactose & 100 & - \\
\hline Sodium starch glycolate & 30 & - \\
\hline Croscarmellose sodium & - & 4.8 \\
\hline Sodium lauryl sulphate & 7.3 & - \\
\hline Magnesium stearate & 7.3 & - \\
\hline Aerosil & 1.46 & 0.27 \\
\hline
\end{tabular}

\begin{tabular}{|c|c|c|c|c|}
\hline \multirow{2}{*}{ Table 2: Effect of variable parameters on mean peak area of linezolid and levami- } \\
sole hydrochloride \\
\hline Variable Parameters & \multicolumn{2}{|c|}{ Linezolid } & \multicolumn{2}{c|}{ Levamisole hydrochloride } \\
\cline { 2 - 5 } & Peak area* & \%RSD & Peak area* & $\% R S D$ \\
\hline $\mathrm{pH} 3.8$ & $378579.3 \pm 3722.39$ & 0.98 & $81294.7 \pm 612.45$ & 0.75 \\
\hline $\mathrm{pH} 4.2$ & $381862.3 \pm 4821.19$ & 1.26 & $68086.7 \pm 612.49$ & 0.90 \\
\hline Flow rate $0.7 \mathrm{~mL} / \mathrm{min}$ & $436734.7 \pm 5222.01$ & 1.19 & $82619.3 \pm 1618.06$ & 1.95 \\
\hline Flow rate $0.9 \mathrm{~mL} / \mathrm{min}$ & $354807.0 \pm 1531.87$ & 0.43 & $56501.0 \pm 728.38$ & 1.28 \\
\hline $234 \mathrm{~nm}$ & $322414.3 \pm 4902.13$ & 1.52 & $73293.7 \pm 1425.45$ & 1.94 \\
\hline $238 \mathrm{~nm}$ & $456560.7 \pm 2251.2$ & $0.49 \%$ & $53167.7 \pm 773.72$ & 1.45 \\
\hline
\end{tabular}

*Data is represented as Mean $\pm S D, n=3$.

values of linezolid and levamizole hydrochloride were found to be $1.925 \mu \mathrm{g} / \mathrm{mL}$ and $0.157 \mu \mathrm{g} / \mathrm{mL}$, respectively. The results evidence that the present method is sensitivity.

\section{Application of method in estimation of linezolid and levamisole hydrochloride in fixed dose combination}

The present HPLC developed method was successfully applied for the estimation of drugs present in the multilayer tablets. Samples were analysed as three independent analysis and the drug content was calculated. The drug content of linezolid and levamizole hydrochloride were found to be $103.66 \pm 0.59 \%$ and 108.21 $\pm 1.22 \%$, respectively. The drug content of levamisole hydrochloride was found to be more than the specifications for a finished product (i.e. $\pm 5 \%$ ). This may be due to manual error or weight/content variations in the manufactured tablets.

\section{CONCLUSION}

Due to increase in cases of antibiotic resistance (resistance towards linezolid and vancomycin) and immune evasion by MRSA, it is postulated that combining an antibiotic and immune stimulant as a single unit dosage form to treat MRSA infection can become a novel therapeutic approach. To formulate a fixed dose combination of antibiotic and immunostimulant, linezolid was selected as antibiotic and levamisole hydrochloride was selected as immunostimulant. Chromatographic method was developed and validated for analysis of drugs in multilayer tablet. The validation results of developed HPLC method confirms that the present method is simple, rapid, specific, precise and robust. The study also concludes that HPLC method can be used for routine quality control analysis of linezolid and levamisole hydrochloride in pharmaceutical dosage forms.

\section{ACKNOWLEDGEMENT}

The authors would like to acknowledge Glen mark Generics Ltd., Mumbai and Aurochem Pharmaceuticals Pvt Ltd., Mumbai for providing Linezolid and Levamisole hydrochloride, respectively as gift samples. The authors are also thankful to Lupin Research Park, Pune for the provision of Croscarmellose sodium. The 
authors also would like to thanks Manipal University, Manipal, and Karnataka, India for providing the necessary research facilities to complete this research work.

\section{CONFLICT OF INTEREST}

The authors declare no conflict of interest.

\section{ABBREVIATIONS USED}

ABR: Antibacterial resistance; AMR: Antimicrobial resistance; BDS: Base Deactivated Silica; HIV: Human Immunodeficiency Virus; HPLC: High Performance Liquid Chromatography; HPMC: Hydroxy propyl methylcellulose; ICH: International Council For Harmonization; LOD: Limit of Detection; LOQ: Limit of Quantitation; MRSA: Methicillin-resistant Staphylococcus aureus; PRSP: Penicillin-resistant Staphylococcus pneumoniae; RSD: Relative Standard Deviation; SD: Standard Deviation; UV: Ultra violet; VRE: Vancomycinresistant enterococci.

\section{REFERENCES}

1. Kapil A. The challenge of antibiotic resistance: need to contemplate. Indian Journal of Medical Research. 2005;121(2):83. PMid:15756040

2. Antimicrobial resistance global report on surveillance (2014). Available from: http://apps.who.int/iris/bitstream/10665/112642/1/9789241564748_eng.pdf. Accessed on 06th March 2014.

3. Siddique H. (2014). Available from: https://www.theguardian.com/ society/2014/dec/11/drug-resistant-infections-deaths-soar-10m-by-2050report. Accessed on 07th March 2014.

4. Gelband H, Delahoy M (2014). Available from: https://www.cddep.org/sites/ default/files/abrinlmics_cddep_gelband_and_delahoy_9-14.pdf. Accessed on 14th March 2014

5. Lee $\mathrm{CR}$, Cho $\mathrm{IH}$, Jeong BC, Lee SH. Strategies to minimize antibiotic resistance. International journal of environmental research and public health. 2013;10(9):4274-305. https://doi.org/10.3390/ijerph10094274; PMid:24036486 PMCid:PMC3799537.

6. Ogbodo S, Okeke AC, Ugwuoru CDC, Chukwurah EF. Possible alternatives to reduce antibiotic resistance. Life Sci Med Red. 2011. LSMR-24: 1-9.

7. Linezolid. Available from: https://en.wikipedia.org/wiki/Linezolid. Accessed on 17th March 2014

8. Diekema DJ, Jones RN. Oxazolidinone antibiotics. The Lancet. 2001;358(9297):1975-82. https://doi.org/10.1016/S0140-6736(01)06964-1.

9. Kaplan SL, Deville JG, Yogev R, Morfin MR, Wu E, Adler S, Edge-Padbury B, Naberhuis-Stehouwer S, Bruss JB, Linezolid Pediatric Study Group. Linezolid versus vancomycin for treatment of resistant Gram-positive infections in children. The Pediatric infectious disease journal. 2003;22(8):677-86. https:// doi.org/10.1097/01.inf.0000078160.29072.42; PMid:12913766.
10. Dotis J, losifidis E, loannidou M, Roilides E. Use of linezolid in pediatrics: a critical review. International Journal of Infectious Diseases. 2010;14(8):e638-48. https://doi.org/10.1016/j.jij.2009.10.002; PMid:20106697.

11. Struwig MC, Botha PL, Chalkley LJ. In vitro activities of 15 antimicrobial agents against clinical isolates of South African enterococci. Antimicrobial agents and chemotherapy. 1998;42(10):2752-5. PMid:9756791 PMCid:PMC105933.

12. Chien JW, Kucia ML, Salata RA. Use of linezolid, an oxazolidinone, in the treatment of multidrug-resistant gram-positive bacterial infections. Clinical Infectious Diseases. 2000;30(1):146-51. https://doi.org/10.1086/313597; PMid:10619743.

13. Clemett D, Markham A. Linezolid. Drugs. 2000;59(4):815-27. https://doi. org/10.2165/00003495-200059040-00007; PMid:10804037

14. Muller-Serieys C, Drugeon HB, Etienne J, Lascols C, Leclercq R, Nguyen J, Soussy CJ. Activity of linezolid against Gram-positive cocci isolated in French hospitals as determined by three in-vitro susceptibility testing methods. Clinical microbiology and infection. 2004;10(3):242-6. https://doi.org/10.1111/ j.1198-743X.2004.00751.x; PMid:15008946.

15. Brunner CJ and Muscoplat CC. Immunomodulatory effects of levamisole. J Am Vet Med Assoc.1980;176:1159-62. PMid:7216893.

16. Day MJ. Immunomodulatory therapy. In: Maddison JE, Page SW, Church DB (Ed.) Small animal clinical pharmacology. Canada: Elsevier. 2nd Ed. pp. 270-86. https://doi.org/10.1016/b978-070202858-8.50014-2; https://doi. org/10.1111/j.1365-3164.2004.00410_2-1.x.

17. Shah D, Londhe V, Mazumder R, Parikh R. Can levamisole alone maintain the immunity. International Journal of Pharmacy and Pharmaceutical Sciences. 2011;3:161-4.

18. Kumar L, Reddy MS, Managuli RS, Pai G. Full factorial design for optimization, development and validation of HPLC method to determine valsartan in nanoparticles. Saudi Pharmaceutical Journal. 2015;23(5):549-55. https://doi. org/10.1016/j.jsps.2015.02.001; PMid:26594122 PMCid:PMC4605903.

19. Dolan J. Available from: http://www.hplc.eu/Downloads/ACE_Guide_Apps. pdf. Accessed on 18th January 2014.

20. ICH Guidelines, Q2 (R1). Available from: http://www.ich.org/fileadmin/Public Web_Site/ICH_Products/Guidlines/Quality/Q2_R1/Step4/Q2_R1_Guideline. pdf. Accessed on 07th September 2014

21. Kasa S, Reddy MR, Kadaboina RS, Murki V, Mulukutla VS. Stability-indicating LC method for the estimation of Bendamustine hydrochloride and its related impurities. Journal of chromatographic science. 2014;52(7):573-83. https:// doi.org/10.1093/chromsci/bmt075; PMid:23825351.

22. Pydimarry SPR, Cholleti VK, Vangala RR. Stability-indicating UPLC method for determining related substances and degradants in dronedarone. $\mathrm{J}$ Chrom Sci. 2013; 52: 666-675. https://doi.org/10.1093/chromsci/bmt097; PMid:23863770.

23. Solanki TB, Shah PA, Patel KG. Central composite design for validation of HPTLC method for simultaneous estimation of olmesartan medoxomil, amlodipine besylate and hydrochlorothiazide in tablets. Indian journal of pharmaceutical sciences. 2014;76(3):179. PMid:25035528 PMCid:PMC4090824

24. Shirodkar RK, Shetty P, Kumar L, Mutalik S, Lewis SA. Development and validation of a reverse phase HPLC method for the estimation of lacidipine in nanoformulations. Latin Am J Pharm. 2015; 34:1162-6.

25. Awotwe-Otoo D, Agarabi C, Faustino PJ, Habib MJ, Lee S, Khan MA Shah RB. Application of quality by design elements for the development and optimization of an analytical method for protamine sulfate. Journal of pharmaceutical and biomedical analysis. 2012;62:61-7. https://doi. org/10.1016/j.jpba.2012.01.002; PMid:22316620. 


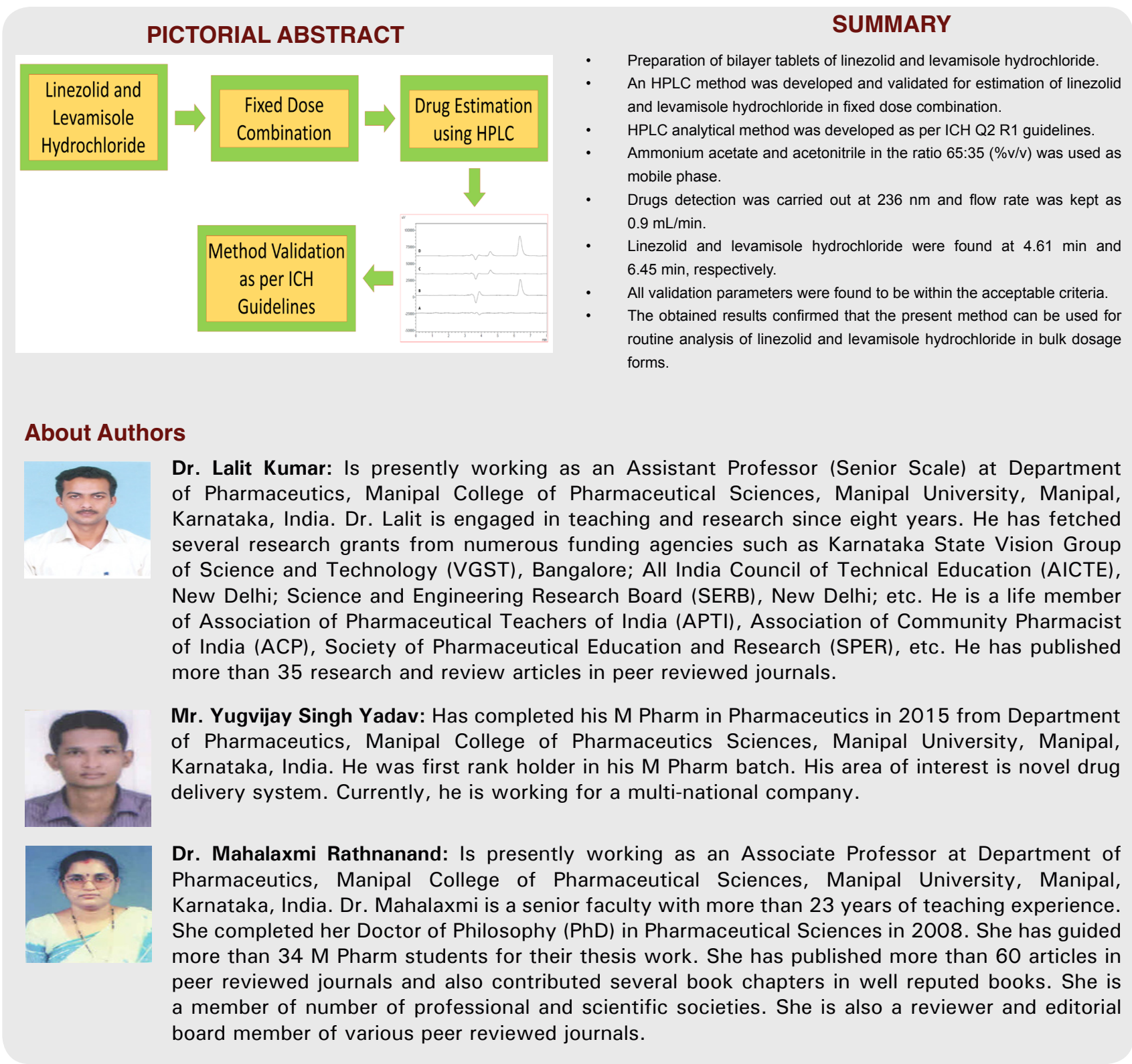

Cite this article: Kumar L, Yadav YS, Rathnanand M. Simultaneous Determination of Linezolid and Levamisole Hydrochloride in a Fixed Dose Combination. Indian J of Pharmaceutical Education and Research. 2017;51(4):613-9. 